\title{
Dynamics of psychophysiological functions and indicators of physical and technical readiness in young football players aged $12-13$ and $15-16$ years during a 3-month training process
}

\author{
DOI: https://doi.org/10.5114/pq.2019.86464
}

\author{
Zhanneta Kozina', Marian Cretu², Danil Safronov³, Ivan Gryn', Yurii Shkrebtii ${ }^{4}$, Nataliya Bugayets ${ }^{5}$, \\ Tatiana Shepelenko ${ }^{6}$, Andrii Tanko \\ ${ }^{1}$ Department of Olympic and Professional Sport and Sport Games, H.S. Skovoroda Kharkiv National Pedagogical \\ University, Kharkiv, Ukraine \\ ${ }^{2}$ Faculty of Sciences, Physical Education and Informatics, University of Pitesti, Pitesti, Romania \\ ${ }^{3}$ Department of Surgical Diseases and Topographic Anatomy, Kharkiv National University, Kharkiv, Ukraine \\ ${ }^{4}$ Department of Water Sports, National University of Ukraine on Physical Education and Sport, Kiev, Ukraine \\ ${ }^{5}$ Department of Choreography, H.S. Skovoroda Kharkiv National Pedagogical University, Kharkiv, Ukraine \\ ${ }^{6}$ Department of Physical Culture, Ukrainian State University of Railway Transport, Kharkiv, Ukraine \\ ${ }^{7}$ Department of Administrative Law and Process, Kharkiv National University of Internal Affairs, Kharkiv, Ukraine
}

\section{Abstract}

Introduction. The purpose of the research was to provide a comparative characteristic of the dynamics of psychophysiological functions and indicators of physical and technical readiness of young footballers aged 12-13 and 15-16 years during 3 months of training.

Methods. The study involved 24 football players; 12 were 12-13 years old, 12 were 15-16 years old. Parameters characteristic of determining the psychophysiological status, indicators of the nervous system work capacity, and attention indicators were analysed with the help of computer programs for psychophysiological testing. Also, the level of physical preparedness $(60-\mathrm{m}$ running, 1000-m running, shuttle running, pull-ups, standing long jump), and of technical preparedness (juggling, running throw) were established. Testing was carried out at the beginning of the preparatory period and at the beginning of the competition period of an annual training process cycle. The gap between the tests was 3 months.

Results. Changes of psychophysiological indicators and indicators of physical and technical fitness that occurred in the observed period were more expressed among the 12-13 years old football players than in those aged 15-16 years.

Conclusions. At the age of 12-13 years, emphasis should be put on the development of psychophysiological functions since at an older age the level of these functions is more difficult to influence, which can be decisive for the perfection of the athlete in football.

Key words: football, psychophysiological indicators, training, preparation

\section{Introduction}

Football requires the development of physical qualities and psychophysiological functions [1, 2] because complex technical techniques in this discipline can only be carried out with perfect central nervous system control of movements $[3,4]$. That is why the authors, who were involved with the problem of controlling movements by the central nervous system $[5,6]$, considered it necessary to determine the status of the nervous system in the formation of motor skills. The status of the nervous system can be determined with many methods [7, 8]. In modern studies, psychophysiological methods are often used to establish the status of an athlete's nervous system, as well as the general functional status [8-11].

Psychophysiology is a branch of psychology concerned with the physiological bases of psychological processes [12-14]. Mental chronometry is studied by using measurements of reaction time, which is the time elapsed between the presentation of a sensory stimulus and the subsequent behavioural response, and is an aspect involved in experimental psychophysiology [9, 12, 13]. Mental chronometry focuses on response time in perceptual-motor tasks to infer the content, duration, and temporal sequencing of cognitive operations. The results of mental chronometry were applied as indicators of psychophysiological functions [8, 9, 14].

The development of psychophysiological functions is determined by hereditary characteristics $[8,13]$. But at the time of the reaction to the visual and auditory stimuli, they are influenced by the factors of special training. Many researchers [13-15] have found that sports such as sports games (basketball, volleyball, football, etc.) or martial arts influence the development of psychophysiological functions. This is followed by a reduction in the reaction time for visual and auditory stimuli, increased speed of operational thinking, reduced response time of choice, increased stability of reaction time during multiple tests for determination of reaction time, reduction of errors in response to various stimuli [16-18].

Correspondence address: Zhanneta Kozina, Department of Olympic and Professional Sport and Sport Games, H.S. Skovoroda Kharkiv National Pedagogical University, Altshevskih Str. 29, Kharkiv, 61002, Ukraine, e-mail: zhanneta.kozina@gmail.com 
Football belongs to the sports in which the success of competitive activities depends not only on the development of motor qualities, but also on the work of the nervous system, which is reflected in increasing the speed of response to various stimuli, the speed of switching attention $[1,3,5]$. In the process of training young footballers, the amount of special skills that affect the development of psychophysiological functions constantly increases. For the rational management of the training process of young players of all ages, it is necessary to have information about the peculiarities of the dynamics in the improvement of physical development indicators, and physical and technical preparedness of players [19-21]. These problems are widely covered in modern scientific research. Pons et al. [22] and da Silva et al. [23] showed that there are differences in the somatic typology among football players of all ages and different regions. Grabara [24] revealed that boys playing football have a lower body mass index, more symmetrical position of the body in the frontal plane, and higher horizontal symmetry of the shoulder blades compared with boys who do not play football. Neogi et al. [25] showed the impact of different training systems on the physical and physiological aspects and indicators of physical and technical fitness in young players. Clemente et al. [26] reported a positive effect of small-sided and conditioned games on the internal load (heart rate and perceived exertion), external load (Global Positioning System variables), and lower limb power (squat jump and countermovement jump). Jaworska et al. [27] proved that progressive muscle relaxation therapy increases the distance measured by the Cooper test. Chromik et al. [28] maintain that the rational construction of the training process leads to improved posture. Training overloads may often result in disorders of the organ of locomotion and affect the correct body posture in athletes. This, in turn, may cause pains and injuries. Gonçalves et al. [29] conducted a review of modern research and concluded that most of the studies employed video footage obtained from soccer matches, which were occluded at a given point for study participants to quickly and precisely elicit the positions of opponents, teammates, and the ball, as well as anticipate actions (dribbling, shooting, passing) from surrounding players (teammates and opponents). In addition, the studies compared the performance of players from both high and low competitive levels in anticipation tasks.

But the question remains about the existence of differences in the dynamics of the development of psychophysiological functions in young footballers of various ages. On the basis of the analysis of literature data, we put forward the following hypothesis: there are differences in the dynamics of psychophysiological functions in young football players of various ages under the influence of special training loads characteristic of football.

The purpose of the study was to provide a comparative characteristic of the dynamics of psychophysiological functions and indicators of physical and technical readiness of young footballers aged $12-13$ and $15-16$ years during 3 months of training.

\section{Subjects and methods}

\section{Participants}

The study involved 24 football players; 12 of them were 12-13 years old, 12 participants were $15-16$ years old. All children had started to play football at the age of 10-11, that is, the football practice was 1-2 years for players aged 12-13 years and 5-6 years for those aged 15-16 years.

\section{Experimental protocol}

Initially, the level of psychophysiological functions, and physical and technical preparedness of young football players aged 12-13 and 15-16 years at the beginning of the preparatory period of a training process annual cycle was determined. Young footballers were tested for 2 training sessions. On the first day, testing was conducted on the level of technical preparedness. On the second day, tests on the level of physical fitness were performed. Psychophysiological testing was conducted on the third day between 17:00 and 19:00.

Young footballers trained in the programs of preparation for competitions in accordance with standard curricula for children's and youth sports schools. The training lasted for 3 months, till the end of the preparatory period and the beginning of the competition period.

The next step was to conduct a re-test at the start of the competition period. Young players again passed tests similar to the first ones. The purpose was to determine the level of physical and technical preparedness, and development of psychophysiological functions.

Subsequently, the statistical processing of the data was carried out to identify the characteristics of the dynamics of psychophysiological indicators, as well as the indicators of physical and technical fitness of the young athletes. On the basis of the obtained data, practical recommendations were developed for constructing a training process for young footballers in accordance with the identified peculiarities of physical and technical preparedness and the development of psychophysiological functions.

\section{Determination of the physical preparedness level}

1. Running at $60 \mathrm{~m}$. This test was conducted on treadmills, running from a high start. The assistant coach gave the team the 'Ready, steady, go!' command. At the finish, the coach determined with a stopwatch the time for which the footballers ran. The races were held by two coaches.

2. Running at $1000 \mathrm{~m}$. The players started on the 'Go!' command. The final time results were determined by the assistant coach.

3. Shuttle run. The test was conducted on a football field and performed $30 \times 4$, that is, the players ran 4 times in 30 meters. The start was arbitrary on a whistle. The outcome was measured in seconds, and the participants were to run the distance as fast as possible.

4. Lifting up on a crossbar. This was a simple test for physical strength. The result was measured in the quantities of correctly executed repetitions.

5. Standing long jump. This test was carried out from place. The player stood in front of a line and had 3 jumping attempts. The best result was analysed, measured in centimetres.

\section{Determination of the technical preparedness level}

1. Juggling. The main task in this test was to lift the ball so that it did not fall to the ground. This was done by feet, and the athlete was to lift the ball as many times as possible.

2. Running throw. Being out of the line of the field, the player was to throw a ball running, as far as possible; the distance was measured in meters. 


\section{Psychophysiological research methods}

Psychophysiological research methods were used to determine the level of attention, ability to concentrate, mental performance, and the speed of reaction. Research of mental working capacity was conducted with the method of Schulte table. The ability to concentrate was studied with the proofreading (correction) method (Bourdon test) [16, 30, 31].

The following parameters characteristic of the psychophysiological status, typological features of the nervous system, indicators of the nervous system efficiency, and attention indicators $[25,26]$ were set by using the Psychodiagnostics computer software:

- A set of indices for the time of a simple visual-motor reaction (mean of 30 attempts [ms], standard deviation [ms], number of errors); duration of exposure (signal): 900 ms.

- A set of indicators of a complex visual-motor reaction of selecting 1 element from 3 and selecting 2 elements from 3 (mean value of 30 attempts [ms], standard deviation [ms], number of errors); duration of exposure (signal): $900 \mathrm{~ms}$.

- A set of indicators of a complex visual-motor reaction of selecting 2 elements out of 3 in the feedback mode, i.e. as the response time changes, the signal delivery time changes. The short version is carried out in the feedback mode, when the duration of exposure changes automatically depending on the response of the subject: after a correct answer, the duration of the next signal is reduced by $20 \mathrm{~ms}$, and after a wrong one, it increases by the same amount. The range of the signal exposure change during the subject's operation is $20-900 \mathrm{~ms}$, with a pause between exposures of $200 \mathrm{~ms}$. The correct answer is to press the left (right) mouse button during the display of a certain exposure (image) or during a pause after the current exposure. In this test, the time to reach the minimum exposure of the signal and the time of the minimum exposure of the signal reflect the functional mobility of the nervous processes; the number of errors reflects the strength of the nervous processes (the lower these parameters, the higher the mobility and strength of the nervous system). The duration of the initial exposure is $900 \mathrm{~ms}$; the amount of change in the duration of the signals with correct or erroneous responses is $20 \mathrm{~ms}$; pause between the presentation of signals lasts $200 \mathrm{~ms}$; the number of signals is 50 . The indicators are fixed: the average value of the latent period (ms), root-mean-square deviation (ms), number of mistakes, time of test execution (s), minimum exposure time (ms), time of exposure to the minimum exposure (s).

- A set of indicators of a complex visual-motor reaction of selecting 2 elements out of 3 in the feedback mode, i.e. as the response time changes, the signal delivery time changes. The long version is carried out in the feedback mode, when the duration of exposure changes automatically depending on the response of the subject: after a correct answer, the duration of the next signal is reduced by $20 \mathrm{~ms}$, and after a wrong one, it increases by the same amount. The range of the signal exposure change during the subject's operation is 20-900 ms, with a pause between exposures of $200 \mathrm{~ms}$. The correct answer is to press the left (right) mouse button during the display of a certain exposure (image) or during a pause after the current exposure. In this test, the time to reach the minimum exposure of the signal and the time of the minimum exposure of the signal reflect the functional mobility of the nervous processes; the number of errors reflects the strength of the nervous processes (the lower these parameters, the higher the mobility and strength of the nervous system). In addition, the total time of the test reflects a combination of strength and mobility of the nervous pro- cesses. The duration of the initial exposure is $900 \mathrm{~ms}$; the amount of change in the duration of the signals with correct or erroneous responses is $20 \mathrm{~ms}$; pause between the presentation of signals lasts $200 \mathrm{~ms}$; the number of signals is 120. The indicators are fixed: the average value of the latent period (ms), root-mean-square deviation (ms), number of mistakes, time of test execution (s), minimum exposure time (ms), time of exposure to the minimum exposure (s).

The indicators of mental working capacity were also determined in accordance with the Schulte test. In this test, the subject is provided with $5 \times 5$ tables of 25 digits (from 1 to 25 ) arranged in a random order. The task is to mark the numbers from 1 to 25 . After passing the first table, the second with a different order of digits immediately appears, and so on. In total, the subject passes 5 tables. The reported outcomes were: the time of work on each of the 5 tables (min), the efficiency of work as the arithmetic average of the time of operation on 5 tables (min), the performance of the nervous system as an individual time of work on the $4^{\text {th }}$ and $1^{\text {st }}$ tables, and the workability of the nervous system as an individual work time for the $2^{\text {nd }}$ and $1^{\text {st }}$ tables.

The response time of the selection of signals appearing at various points of a screen in a button selection program (Ermakov test) was also determined [30].

The psychophysiological status of a person was diagnosed in accordance with the program of measuring the time of the reaction in choosing a point in space ('Select a button'; Ermakov test). This test includes conducting one series or several series of tests, which, along with the algorithm, consist of a sequence of actions:

- On a touch screen of an electronic device, an image of the object for response is displayed, each time in a new location. The time interval between the appearances of the object is not constant.

- Response to the appearance of the object on the screen is carried out by touching the image of the object.

- The number of items in each series, the number of correct touches, and the number of series are summed up.

The parameters to be recorded are: the total test run time, the total number of correct answers, the number of errors.

\section{Statistical analysis}

When comparing the average values of the tested parameters of young football players' groups of 12-13-yearolds and 15-16-year-olds, Student's test was used. The reliability of differences in the testing rates was determined at the beginning of the preparatory period and at the beginning of the competition period with the Student's method for independent samples. Intra-group differences were established for football players within each age group between the indicators obtained at the beginning of the preparatory period and at the beginning of the competitive period. The processing of indicators was carried out with the help of the Excel 2016 and SPSS-17 software.

\section{Ethical approval}

The research related to human use has complied with all the relevant national regulations and institutional policies, has followed the tenets of the Declaration of Helsinki, and has been approved by the authors' institutional review board.

\section{Informed consent}

Informed consent has been obtained from the legal guardians of all individuals included in this study. 


\section{Results}

It was found that the psychophysiological indicators for young football players aged 15-16 years were significantly better than those for players aged 12-13 years (Figures $1-5)$. However, the dynamics of change in these indicators between the preparatory and the competitive period was more pronounced in footballers aged 12-13 years. Typically of the results in the Ermakov test, in the 12-13-yearold footballers, the effectiveness of the test of reaction to an object that changed its position in space increased from the preparatory to the competitive period more than that among football players aged 15-16 years (Figure 1).

The number of significant changes in the tests on the reaction rate in different signalling modes was also greater in 12-13-year-old footballers. This indicates that the reaction rate, the ability to switch attention develops more effectively at the age of 12-13 years than among 15-16-yearolds (Figure 2).

A similar pattern was observed in the Schulte test on mental performance: the dynamics of working time on different tables or the number of significant changes was more pronounced in footballers aged $12-13$ years. This indicates

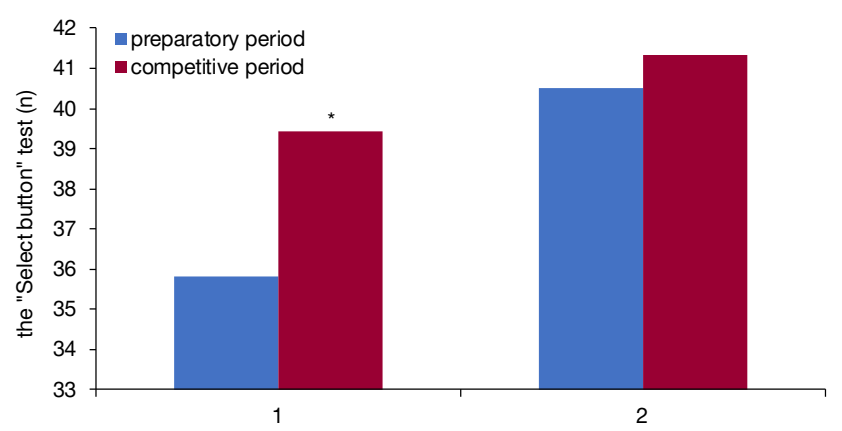

1 - football players aged $12-13$ years

2 - football players aged $15-16$ years

* differences are significant at $p<0.05$

Figure 1. Comparative characteristics of psychophysiological functions (the 'Select button' test) of young footballers aged $12-13$ and $15-16$ years in the preparatory and competitive periods

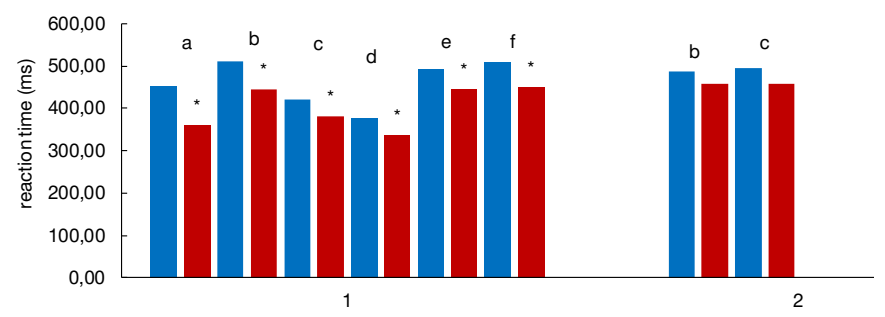

$1-$ football players aged $12-13$ years

2 - football players aged $15-16$ years

a - time of simple visual-motor reaction $(\mathrm{ms})$

$\mathrm{b}$ - time of reaction of choice of 2 elements from $3(\mathrm{~ms})$

$\mathrm{c}$ - time of response selection in the feedback mode $(\mathrm{ms})$

$\mathrm{d}$ - time of minimum signal exposure in the feedback mode (ms)

$\mathrm{e}$ - time of the reaction of choice in the mode of the imposed

rhythm at 50 signals $(\mathrm{ms})$

$\mathrm{f}-$ time of the reaction of choice in the mode of the imposed

rhythm at 120 signals (ms)

* differences are significant at $p<0.05$

Figure 2. Comparative characteristics of psychophysiological

functions (reaction time) of young footballers aged 12-13

and 15-16 years in the preparatory and competitive periods (only significant changes of indicators are presented)

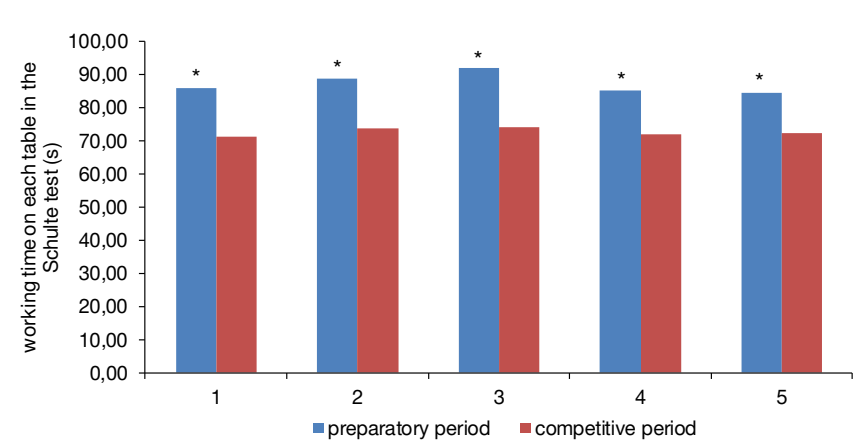

* - differences are significant at $p<0.05$

$1,2,3,4,5$ - working time on each table in the Schulte test

Figure 3. Comparative characteristics of psychophysiological functions (working time on each table in the Schulte test) of young players aged 12-13 years in the preparatory and competitive periods

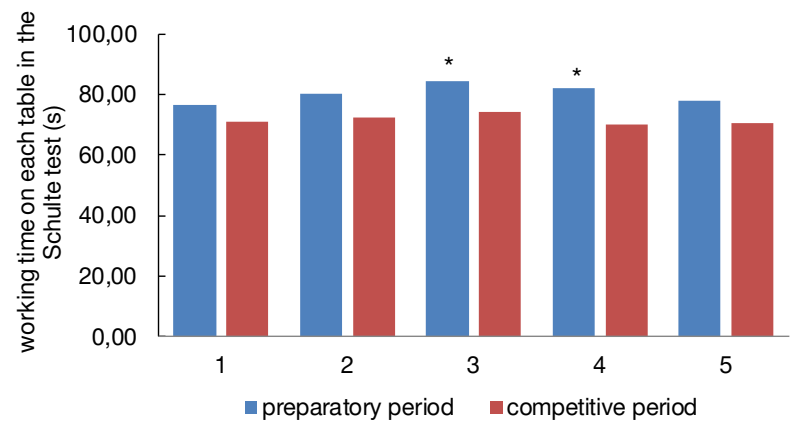

* - differences are significant at $p<0.05$

$1,2,3,4,5$ - working time on each table in the Schulte test

Figure 4. Comparative characteristic of psychophysiological functions (working time on each table in the Schulte test) of young players aged 15-16 years in the preparatory

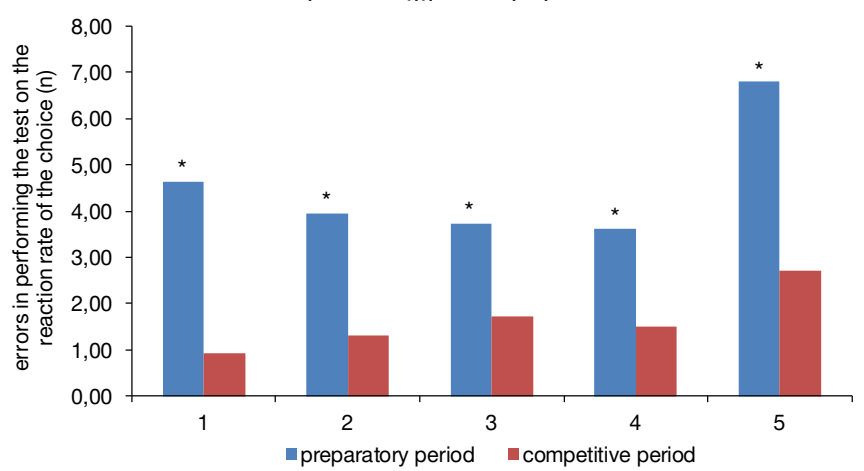

* - differences are significant at $p<0.05$

$1,2,3,4,5-$ stages of work in the test on the rate of complex reaction in a given rhythm

Figure 5. Errors in performing the test on the reaction rate of the choice in young footballers aged $12-13$ years in the preparatory and competitive periods

a higher dynamics of the strength of the nervous system among 12-13-year-olds compared with 15-16-year-olds (Figures 3 and 4 ).

The more pronounced dynamics of the strength of the nervous system at the age of 12-13 years as compared with 15-16 years was also evidenced by the change in the number of errors in the tests on the rate of reaction in different testing modes: among 15-16-year-olds, no significant changes in this indicator were revealed between the preparatory and the competitive periods, whereas in the football players aged 12-13 years, these changes were significant in all the studied parameters (Figure 5). 
Table 1. Indicators of physical, technical, and psychophysiological readiness of young football players aged 12-13 years in the preparatory and competitive periods

\begin{tabular}{|c|c|c|c|c|c|c|}
\hline \multirow{2}{*}{ Name of the test } & \multirow{2}{*}{ Period of testing } & \multicolumn{5}{|c|}{ Statistical indicators } \\
\hline & & $\bar{x}$ & $S$ & $m$ & $t$ & $p$ \\
\hline \multirow{2}{*}{ Running at 60 m (s) } & $P$ & 9.80 & 0.56 & 0.16 & \multirow{2}{*}{2.05} & \multirow{2}{*}{0.05} \\
\hline & C & 9.45 & 0.18 & 0.05 & & \\
\hline \multirow{2}{*}{ Running at $1000 \mathrm{~m}$ (min) } & $P$ & 4.31 & 0.07 & 0.02 & \multirow{2}{*}{2.03} & \multirow{2}{*}{0.06} \\
\hline & C & 4.14 & 0.29 & 0.08 & & \\
\hline \multirow{2}{*}{ Shuttle run $4 \times 30$ m (s) } & $\mathrm{P}$ & 42.52 & 5.38 & 1.55 & \multirow{2}{*}{0.45} & \multirow{2}{*}{0.66} \\
\hline & $\mathrm{C}$ & 41.53 & 5.34 & 1.54 & & \\
\hline \multirow{2}{*}{ Pull-ups ( $n)$} & $\mathrm{P}$ & 6.17 & 2.59 & 0.75 & \multirow{2}{*}{-1.39} & \multirow{2}{*}{0.18} \\
\hline & C & 7.42 & 1.73 & 0.50 & & \\
\hline \multirow{2}{*}{ Standing long jump (m) } & $P$ & 1.67 & 0.26 & 0.08 & \multirow{2}{*}{0.44} & \multirow{2}{*}{0.66} \\
\hline & C & 1.62 & 0.27 & 0.08 & & \\
\hline \multirow{2}{*}{ Juggling $(n)$} & $P$ & 39.17 & 33.72 & 9.73 & \multirow{2}{*}{0.19} & \multirow{2}{*}{0.85} \\
\hline & C & 37.25 & 6.00 & 1.73 & & \\
\hline \multirow{2}{*}{ Running throw (m) } & $\mathrm{P}$ & 16.83 & 8.77 & 2.53 & \multirow{2}{*}{-2.94} & \multirow{2}{*}{0.01} \\
\hline & C & 25.17 & 4.39 & 1.27 & & \\
\hline
\end{tabular}

$\mathrm{P}$ - preparatory period, $\mathrm{C}$ - competitive period

Table 2. Indicators of physical, technical, and psychophysiological readiness of young football players aged 15-16 years in the preparatory and competitive periods

\begin{tabular}{|c|c|c|c|c|c|c|}
\hline \multirow{2}{*}{ Name of the test } & \multirow{2}{*}{ Period of testing } & \multicolumn{5}{|c|}{ Statistical indicators } \\
\hline & & $\bar{x}$ & $s$ & $m$ & $t$ & $p$ \\
\hline \multirow{2}{*}{ Running at $60 \mathrm{~m}$ (s) } & $\mathrm{P}$ & 8.43 & 0.19 & 0.05 & \multirow{2}{*}{-0.59} & \multirow{2}{*}{0.56} \\
\hline & C & 8.50 & 0.40 & 0.11 & & \\
\hline \multirow{2}{*}{ Running at $1000 \mathrm{~m}$ (min) } & $P$ & 3.36 & 0.08 & 0.02 & \multirow{2}{*}{1.57} & \multirow{2}{*}{0.13} \\
\hline & C & 3.30 & 0.09 & 0.03 & & \\
\hline \multirow{2}{*}{ Shuttle run $4 \times 30 \mathrm{~m}(\mathrm{~s})$} & $P$ & 34.56 & 1.88 & 0.54 & \multirow{2}{*}{0.74} & \multirow{2}{*}{0.47} \\
\hline & C & 33.99 & 1.86 & 0.54 & & \\
\hline \multirow{2}{*}{ Pull-ups ( $n$ ) } & $P$ & 11.83 & 3.69 & 1.06 & \multirow{2}{*}{0.06} & \multirow{2}{*}{0.96} \\
\hline & C & 11.75 & 3.70 & 1.07 & & \\
\hline \multirow{2}{*}{ Standing long jump (m) } & $\mathrm{P}$ & 2.32 & 0.07 & 0.02 & \multirow{2}{*}{2.15} & \multirow{2}{*}{0.04} \\
\hline & C & 2.26 & 0.06 & 0.02 & & \\
\hline \multirow{2}{*}{ Juggling $(n)$} & $P$ & 118.75 & 20.74 & 5.99 & \multirow{2}{*}{0.00} & \multirow{2}{*}{1.00} \\
\hline & C & 118.75 & 32.33 & 9.33 & & \\
\hline \multirow{2}{*}{ Running throw (m) } & $P$ & 41.67 & 5.69 & 1.64 & \multirow{2}{*}{-1.15} & \multirow{2}{*}{0.26} \\
\hline & C & 43.83 & 3.16 & 0.91 & & \\
\hline
\end{tabular}

$\mathrm{P}$ - preparatory period, $\mathrm{C}$ - competitive period

The more pronounced changes in psychophysiological indicators between the preparatory and the competitive periods among footballers aged $12-13$ years in comparison with 15-16-year-olds were combined with a similar trend in changing the level of the players' physical and technical preparedness (Tables 1 and 2). So, for players aged 12-13 years, the results of the running throw test improved more than among those aged 15-16 years. The same applies to other tests on the level of physical and technical preparedness.

\section{Discussion}

The research confirmed the hypothesis that there are differences in the dynamics of psychophysiological functions, and indicators of physical and technical fitness in young football players of various ages under the influence of special training loads, characteristic of football. It was found that the change in the psychophysiological indicators between 
the preparatory and the competitive periods of the training process annual cycle was expressed more in football players aged 12-13 years than among 15-16-year-olds. The same applies to the dynamics of indicators of physical and technical preparedness. This is due to age-related features of the nervous system. The data obtained support the results of studies by Luzohub et. al. [14] and Korobeynikov et al. $[7,8]$ on differences in the development of the psychophysiological functions of children at different ages. In our study, data were gathered regarding the dynamics of psychophysiological indicators during a 3-month workout. They are new in terms of identifying features of the dynamics of the psychophysiological functions of young football players.

The findings also confirm the results of studies that revealed the effects of various training programs on the level of physical and technical readiness of young football players [19-21], as well as on anthropometric indicators [22-25]. In our study, the athletes trained in accordance with standard programs for football players of a given age. In both age groups, there was a positive dynamics of psychophysiological indicators. However, in the age group of 12-13-year-olds, the change in psychophysiological indicators during 3 months of training was more pronounced than in the group aged $15-16$ years. This may be due to the age characteristics of young footballers because in 12-13 year-olds, the change in psychophysiological functions occurs faster than at an older age [14]. It can also be related to the nature of the training process: as a rule, in the training process of football players aged 12-13 years, more exercises are applied for the development of psychophysiological functions (games, competitions, exercises for agility and speed).

However, in our opinion, the main factor that determines the differences in the dynamics of psychophysiological functions is the age of young athletes. At 12-13 years, the processes of body height fast increase in length and the period of puberty begin. Many physical qualities and motor abilities are most rapidly developing at this age $[17,21]$. The age is particularly favourable for the development of speed and coordination abilities. As these are most closely connected with the inclusion of the nervous system in motion management, the accelerated development of psychophysiological functions is also characteristic of the age of $12-13$ years. At an older age, the pace of development of speed and speedstrength abilities slows down. This can explain the decrease in the development of psychophysiological functions among young football players aged 15-16 years. In their research, Mikheev et. al. [32] showed that the development of speed abilities was associated with an increase in nerve fibre myelination and in the amount of white matter in the brain, which contributes to a rise in the transmission rate of the pulse through the nerve paths. The increase in the reaction rate in various test modes is also due to enhanced pulse rate of the nerve fibres. In this context, the pace of development of psychophysiological functions in 12-13-year-olds is higher than in 15-16-year-olds, although by absolute indicators, the reaction rate is higher in the latter.

In connection with the favourable period of development of speed and coordination abilities at the age of 12-13 years, the training process of young football players of this age focuses on the development of these qualities in particular. This activates the processes of conducting a pulse on nerve fibres and increases the rate of response to various signals $[33,34]$.

\section{Recommendations}

The obtained data allow to give recommendations for the training process of young players aged 12-13 years to underline the development of qualities that require the activation of psychophysiological functions, especially the reaction rate, the speed of switching attention, mental performance, etc. Psychophysiological functions are largely hereditary and their development is therefore difficult at the age of 12-13 years; emphasis should be placed on their development since at an older age, the level of psychophysiological functions is even more challenging to expand, which can play a crucial role in improving the athlete in football.

\section{Limitations}

The study was conducted among young football players aged $12-13$ and $15-16$ years. Thus, the findings apply only to these age groups. For conclusions regarding other age groups, additional research is needed. It is also necessary to compare the effects of various training programs on the dynamics of the psychophysiological functions in young football players within each age group.

\section{Conclusions}

1. The change in the psychophysiological indicators, and indicators of physical and technical fitness between the preparatory and the competitive periods of the training process annual cycle was expressed more in football players aged 12-13 years than among 15-16-year-old athletes. This is due to the age-related peculiarities of the nervous system, as well as to the nature of the training process: in the training process of players aged 12-13 years, more exercises are applied for the development of psychophysiological functions.

2. The training process of young players aged 12-13 years should focus on the development of qualities requiring the activation of psychophysiological functions, especially the reaction rate, the speed of switching attention, and mental performance.

3. At the age of 12-13 years, emphasis should be placed on the development of psychophysiological functions, since at an older age, these are more difficult to expand, which can play a key role in improving the athlete in football.

\section{Acknowledgements}

The study was conducted in accordance with the research work of Ministry of Education and Science of Ukraine for 2017-2018 'Theoretical and methodical bases of application of information, medical, biological, and pedagogical technologies for implementation of individual physical, intellectual, and spiritual potential and formation of a healthy lifestyle' (state registration No. 0117U000650).

\section{Disclosure statement}

No author has any financial interest or received any financial benefit from this research.

\section{Conflict of interest}

The authors state no conflict of interest.

\section{References}

1. Aksoy Y, Agaoglu SA. The comparison of sprint reaction time and anaerobic power of young football players, volleyball players and wrestlers. Kinesiol Slov. 2017; 23(2):5-14. 
2. Campos E, Pereira R, Alves I, Mineiro AS, Scorcine C, Madureira F. Physical and behavioral analysis of young athletes practicing field football, during different training designs [in Portuguese]. Rev Bras Futsal Futebol. 2017;9(32):16-20.

3. Figueira B, Gonçalves B, Masiulis N, Sampaio J. Exploring how playing football with different age groups affects tactical behaviour and physical performance. Biol Sport. 2018;35(2):145-153; doi: 10.5114/biolsport.2018. 71603.

4. Polevoy G. The development of the ability to equilibrium football players 10-11 years with different nervous system. Pak J Med Health Sci. 2018;12(1):496-499.

5. Shadmehr R, Wise SP. The computational neurobiology of reaching and pointing: a foundation for motor learning. Cambridge: MIT Press; 2005.

6. Paul M, Ganesan S, Sandhu JS, Simon JV. Effect of sensory motor rhythm neurofeedback on psycho-physiological, electro-encephalographic measures and performance of archery players. Ibnosina J Med Biomed Sci. 2012;32-39.

7. Korobeynikov G, Korobeynikova LG, Romanyuk LV, Dakal NA, Danko GV. Relationship of psychophysiological characteristics with different levels of motivation in judo athletes of high qualification. Pedagog Psychol MedBiol Probl Phys Train Sports. 2017;21(6):272-278; doi: 10.15561/18189172.2017.0603.

8. Korobejnikov GV, Korobejnikova LG, Kozina ZL. Evaluation and correction of physiological states in sports [in Ukrainian]. Kharkiv: KNPU; 2012.

9. Deary IJ, Der G, Ford G. Reaction times and intelligence differences: a population-based cohort study. Intelligence. 2001;29(5):389-399; doi: 10.1016/S0160-2896 (01)00062-9.

10. Podrigalo LV, Volodchenko AA, Rovnaya OA, Podavalenko OV, Grynova TI. The prediction of success in kickboxing based on the analysis of morphofunctional, physiological, biomechanical and psychophysiological indicators. Phys Educ Stud. 2018;22(1):51-56; doi: 10.15561/20755279.2018.0108.

11. Hedayatpour N, Falla D. Physiological and neural adaptations to eccentric exercise: mechanisms and considerations for training. Biomed Res Int. 2015;2015: 193741; doi: 10.1155/2015/193741.

12. Cacioppo J, Tassinary LG, Berntson GG. The handbook of psychophysiology, $3^{\text {rd }}$ ed. New York: Cambridge University Press; 2007.

13. Shumway-Cook A, Woollacott M. Motor control: theory and practical applications. Baltimore: Williams and Wilkins; 1995.

14. Lyzohub V, Nechyporenko L, Pustovalov V, Suprunovych $V$. Specialized training and bioenergy state of football players with different typological properties of the higher parts of the nervous system. Sci Educ. 2016;8: 107-112; doi: 10.24195/2414-4665-2016-8-21.

15. Ilin EP. Differential psychophysiology, its place and role in the study of the personality of athletes [in Russian]. Sportivnaya i Vozrastnaya Psihofiziologiya. 1974;1:5-24.

16. Kozina Z, Prusik K, Görner K, Sobko I, Repko O, Bazilyuk $\mathrm{T}$, et al. Comparative characteristics of psychophysiological indicators in the representatives of cyclic and game sports. J Phys Educ Sport. 2017;17(2):648655; doi: 10.7752/jpes.2017.02097.

17. Kozina Z, Goloborodko Y, Boichuk Y, Sobko I, Repko O, Bazilyuk T, et al. The influence of a special technique for preparedness and development of psycho-physiological functions of young volleyball players 14-16 years of age. J Phys Educ Sport. 2018;18(3):1445-1454; doi: 10.7752/jpes.2018.03214.

18. Kozina Z, Shepelenko T, Osiptsov A, Kostiukevych V, Repko O, Sobko I, et al. Factor structure of the integral readiness of aerobics athletes (women). J Phys Educ Sport. 2017;17(Suppl 5):2188-2196; doi: 10.7752/jpes. 2017.s5227.

19. Arrieta P, Castellano J, Guridi I, Echeazarra I. Effects of a program based on small-sided games on the physical condition in young football players [in Spanish]. Rev Int Cienc Deporte. 2017;13(50):370-380; doi: 10.5232/ ricyde2017.05004

20. Bolotin A, Bakayev V. Pedagogical conditions necessary for effective speed-strength training of young football players (15-17 years old). J Hum Sport Exerc. 2017; 12(2):405-413; doi: 10.14198/jhse.2017.122.17.

21. Jaafar Z, Kee J, Abdul Hadi H, Ahmad Tajuddin NA. Anthropometrical and fitness level changes following a 12-week walking football program for obese primary school children aged 8-11. Med Sport. 2018;71(3):451460; doi: 10.23736/s0025-7826.18.03285-4.

22. Pons RA, Villacampa SF, Canada AP. Anthropometric profile characterization of youth players from the Angolan Football Academy [in Portuguese]. Rev Bras Futsal Futebol. 2018;10(37):138-149.

23. Da Silva IM, Palma A, Ramos SP, Galvão PVM, Simão $R$, Costa e Silva G, et al. Somatotypological analysis in football athletes with age between nine and twenty years: a transversal study [in Portuguese]. Rev Bras Futsal Futebol. 2019;11(42):111-118.

24. Grabara M. Analysis of body posture between young football players and their untrained peers. Hum Mov. 2012; 13(2):120-126; doi: 10.2478/v10038-012-0012-7.

25. Neogi A, Chakraborty C, Chatterjee S, Dey SK. Anthropometric profiles and pulmonary function parameters of male football \& hockey players according to their specific playing position: a comparative study. Int J Appl Exerc Physiol. 2018;7(3):10-23; doi: 10.30472/ijaep. v7i3.233.

26. Clemente FM, Nikolaidis PT, Linden CMI, Silva B. Effects of small-sided soccer games on internal and external load and lower limb power: a pilot study in collegiate players. Hum Mov. 2017;18(1):50-57; doi: 10.1515/ humo-2017-0007.

27. Jaworska L, Hawrylak A, Burzyński B, SzczepańskaGieracha J. Effect of progressive muscle relaxation on pain threshold and effectiveness of footballers' training. Hum Mov. 2015;16(4):225-228; doi: 10.1515/humo2015-0043.

28. Chromik K, Burdukiewicz A, Pietraszewska J, Stachoń A, Wolański P, Goliński D. Characteristics of anteroposterior curvatures of the spine in soccer and futsal players. Hum Mov. 2017;18(4):49-54; doi: 10.1515/humo2017-0039.

29. Gonçalves E, Gonzaga AS, Cardoso FSL, Teoldo I. Anticipation in soccer: a systematic review. Hum Mov. 2015;16(2):91-101; doi: 10.1515/humo-2015-0032.

30. lermakov SS, Kozina ZhL, Ceslitska M, Mushketa R, Krzheminski M, Stankevich B. Computer program development for determination of psycho-physiological possibilities and properties of the nervous system of people with different levels of physical activity [in Russian]. Zdorovye, Sport, Reabilitacya. 2016;2(1):14-19.

31. Kozina Z, lermakov S, Bartik P, Yermakova T, Michal J. 
Influence of self-regulation psychological and physical means on aged people's functional state. J Hum Sport Exerc.2018;13(1):99-115; doi:10.14198/jhse.2018.131.10.

32. Mikheev M, Mohr C, Afanasiev S, Landis T, Thut G. Motor control and cerebral hemispheric specialization in highly qualified judo wrestlers. Neuropsychologia. 2002;40(8): 1209-1219; doi: 10.1016/S0028-3932(01)00227-5.

33. Bos MW, Dijksterhuis A, van Baaren R. Food for thought? Trust your unconscious when energy is low. J Neurosci Psychol Econ. 2012;5(2):124-130; doi: 10.1037/a0027388.

34. Hornberger TA, Chien S. Mechanical stimuli and nutrients regulate rapamycin-sensitive signaling through distinct mechanisms in skeletal muscle. J Cell Biochem. 2006; 97(6):1207-1216; doi: 10.1002/jcb.20671. 